\title{
History of Oral and Maxillofacial Surgery - A Review
}

\author{
Dr. Rahul Tiwari ${ }^{1}$, Dr. Chaitanya Pendyala ${ }^{2}$, Dr. G Gurukarthik ${ }^{3}$, \\ Dr. Arka Bhattacharjee ${ }^{4}$. \\ ${ }^{I}$ (Department Of Oral And Maxillofacial Surgery, Sibar Institute Of Dental Sciences, Ntruhs, Guntur, A.P, \\ India) ${ }^{l}$ \\ ${ }^{2}$ (Department Of Public Health Dentistry, Sibar Institute Of Dental Sciences, Ntruhs, Guntur, A.P, India) ${ }^{2}$ \\ ${ }^{3}$ (Department Of Oral And Maxillofacial Surgery, Sibar Institute Of Dental Sciences, Ntruhs, Guntur, A.P, \\ India $3^{1}$ \\ ${ }^{4}$ (Department Of Conservative Dentistry And Endodontics, Sibar Institute Of Dental Sciences, Ntruhs, Guntur, \\ A.P, India $)^{4}$
}

\begin{abstract}
Aim: To review the history of oral and maxillofacial surgery since beginning till date to analyze the progress and development arranged in systematic, chronological, comprehensive and reliable form

Objectives : To supply this need and to preserve the memory and perpetuate the names of the men who wrought so strenuously and devotedly to initiate and achieve the wonderful improvement, discoveries and inventions that made oral and maxillofacial surgery what it is today, is the object of this publication.

Material and Methods: Collection of data via various websites and books available.

Conclusion: In this world of competition we come across various new researches and advanced technology for which to know the basic history is very important.

Keywords: History, oral surgery, maxillofacial surgery, reconstructive surgery, craniofacial surgery.

\section{Introduction}

Oral and Maxillofacial Surgery is not since years but is since eras in the history. During its illustrious lifespan, it has grown from a fledging dental unit to a leading destination for clinical excellence, breakthrough research, and training. To those who have trained and taught within its walls, there is an enduring connection to the history of the hospital as well as to the evaluation of oral and maxillofacial surgery as a specialty of dentistry and medicine. It's standing as a major force in defining and shaping oral and maxillofacial surgery results from the continuous legacy of distinguished graduates who today serve as academic leaders, deans, outstanding clinicians, and researchers across the specialty.
\end{abstract}

\section{Brief on oral surgery:}

A Distinguished History of Innovation, Excellence, and Quality Care is summarized here. Oral surgery is a practice that has been around for centuries. Oral surgery is a generic term for a number of different surgeries and procedures. According to American dental association maxillofacial and oral surgery is one of nine dental specialties. As defined by Dictionary reference, oral surgery is a branch of dentistry that deals with the diagnosis and treatment of oral conditions requiring surgical intervention. AAOMS recognizes that oral and maxillofacial surgeons deal with wisdom teeth, facial pain, misaligned jaws, facial injuries, implants, oral cancer, tumors, cysts and cosmetic surgery of the face.

\section{History of oral surgery:}

The history of oral surgery begins from $500 \mathrm{BC}$ to $300 \mathrm{BC}$ according to The American Dental Association's history of dentistry. During this time, Hippocrates and Aristotle wrote about various dental topics including treating decayed teeth, gum disease, extracting teeth and the use of wire to support loose teeth and fractured jaws. In 1210, A Guild of Barbers was created in France. These barbers split into two groups; surgeons for more complex operations, and surgeons who carried out simpler procedures. In 1575 Ambrose Pare (the Father of Surgery) published Complete Works. This book contains information on tooth extraction, treatments of tooth decay and jaw fractures. In 1728, the oral surgeon Pierre Fauchard wrote a treatise called "The Surgeon Dentist." His book included basic anatomy of the mouth, as well as surgery techniques. In 1840, The American Society of Dental Surgeons is founded. Today oral surgeries are much more advanced and research and technology continues to grow.The removal of wisdom teeth, apicectomy, Temporomandibular Joint Disorder, trauma in the face, oral pathology, tooth implants, anesthetics and grafts of the bone are all types of oral surgery. These are some of the main surgeries, although other surgeries, including cosmetic surgeries fall into the oral surgery category.Oral surgery serves numerous purposes for dental patients. AAOMS lists the following 
purposes of oral surgery: reconstructive surgery, tumor removal, dental implant placement, diagnosis and treatment of infections, repairs to the face, jaw, and mouth and the correction of deformities. ${ }^{1}$

\section{Brief on maxillofacial surgery:}

Various surgeons and their team have been performing oral and maxillofacial surgery in various parts of the world since years, and it's been a very rewarding experience for every surgeon. Oral and maxillofacial surgery isn't what it used to be. Today's knowledge and available technologies have created a comfortable, welcoming environment for those undergoing treatments such as wisdom teeth removal, dental implants, and surgery. When doctors were first experimenting with these types of treatments, that comfort level was probably completely. According to the Oral and Maxillofacial Surgery Foundation, "The history of oral and maxillofacial surgery originates with the Civil War. During this time revolutionary advancements were made in the treatment of facial fractures for the Union and Confederacy." So many advancements have been developed since then, especially during the 20th century. The oral and maxillofacial surgeon's foundation continues to explain that "As the 20th century progressed, OMSs developed many current trauma techniques through their experiences with the dire injuries of soldiers in World War II, Korea, Viet Nam and the Gulf War." Modern treatment of trauma patients routinely includes the use of advanced and even three dimensional imaging that greatly improves the patient outcomes. Advances in anesthesia allow for patient comfort as well as giving the surgeons the time necessary to perform much more complex and beneficial treatments. These technologies have also been applied to more routine procedures as well. Three dimensional imaging has greatly improved the safety and success of in-office procedures such as the removal of wisdom teeth and the placement of dental implants. Lower wisdom teeth often form roots close to the feeling nerve of the lower lip, and upper wisdom teeth can be close to or partially inside the sinus cavities. Both of these conditions are common and can lead to significant problems if approached incorrectly. ${ }^{2}$

\section{Diagnostic techniques in oral and maxillofacial surgery:}

The use of a 3DCT machines gives a much more complete view of the teeth and their surroundings. This allows for more precise surgery with fewer problems. The placement of dental implants also uses these advanced technologies. Today, few surgeons place all of their dental implants with the use of 3-D pictures and computer generated placement designs. Guidance systems are also used to provide extremely precise placement. This leads to very predictable results. Patient comfort has also been brought to a whole new level. Anesthesia options allow patients to sleep through the procedures. Medications given while the patient is asleep also help in patient comfort after the surgery. Anesthesia options along with precise planning and advanced surgical techniques, greatly improve treatment success as well as patient comfort during and after the procedure. As technology is developed at an ever increasing pace, the need for specialists who can keep up with those changes has also increased. The days of being able to do everything well are long gone, and have been replaced with a need to focus attention on one area of specialty in order to remain at the top of the field. As long as we continue to put value on the best treatment available, and search for and implement the most recent innovations and improvements, we will all benefit from treatments that continue to improve at a tremendous and exciting pace. ${ }^{3}$

\section{History of dentistry:}

Nearly every profession, trade, craft, order or society has had the story of its inception and development recorded in some way, avail- able for consultation and reference by those interested.Dentistry has not now available a historical work in which the record of its mighty achievements is preserved, a history of its rise, progress and development arranged in systematic, chronological, comprehensive and reliable form. To supply this need and to preserve the memory and perpetuate the names of the men who wrought so strenuously and devotedly to initiate and achieve the wonderful improvement, discoveries and inventions that made dentistry what it is today, is the object of this publication. The history of dentistry now is scattered throughout a very extensive and diversified literature. This was exhaustively searched, and the gathered gleanings have been assembled and are presented in these volumes. In a work of this kind divided into subjects that are closely allied, and the lines of demarcation of which' are at times difficult to define, it appears almost impossible to avoid some repetition, especially when^ as in this history, chapters are written by different authors. It is believed, however, that wherever such repetition of matter occurs in this work, it is presented in an entirely different setting and with such diversified side lights, as almost to constitute it new matter.Chicago, after the form relating to the dentistry of the middle ages had been printed, Dr.Edward C. Mills called the attention of the Editor to a medical work published in 1450 by Giovanni d 'Areola of Padua, in which he mentions gold leaf for the filling of decayed teeth. The earliest published references to gold being used for this purpose, as noted in the chapters of this book, is $1532 .^{1,2}$ 


\section{History of oral and maxillofacial surgery:}

The earliest known mention of what is now included in the scope of oral and maxillofacial surgery occurred in Egypt in the so-called Edwin Smith Papyrus (2700 BC). This document, which contains 48case histories written by a military surgeon, mentions the treatment of mandibular fractures with bandages obtained from an embalmer and soaked in honey and egg white [4].The earliest documented treatment of oral diseases dates back to $1200 \mathrm{BC}$ in ancient Greece. These treatments were administered eduin temples known as asclepiads by priests who were followers of Asclepius, the Greek god of medicine. Although these treatments consisted mainly of herbal remedies, there is evidence that tooth extraction was also performed [5].The formal practice of medicine, which at that time included dental treatment, actually began in Greece in the 4th century BCunder the leadership of Hippocrates. He extracted teeth and treated dental abscesses. However, at that time the skill and/or proper forceps needed to readily extract teeth were apparently lacking since he recommended extracting only those teeth that were loose [6].Celsus (25 BC-50 BC) was a leader in Roman medicine, building upon what had been learned from the Greek medical system. Healso considered tooth extraction as dangerous, to be done only as a last resort, and cited cases of resulting jaw fracture leading to death [7]. He recommended filling a carious tooth with linen thread or lead prior to attempted extraction to prevent crushing the crown [8]. Celsus also incised and drained dental abscesses and treated jaw fractures with bandages. The fall of the Roman Empire and Arabic invasion of southern Europe led to the Islamic period of medicine. Among the leading practitioners of that time were Rhazes (865-923 AD), Albacasis (936-1013 AD) and Avicenna (980-1037 AD) [8]. Their expanded surgical scope included treating oral fistulae, ranulas and epuli, and doing frenectomies, as well as the management of infections, jaw fractures and dislocations [9].The Renaissance Period (14th to middle of 17th century) saw a further expansion of the scope of what is now considered to be oral and maxillofacial surgery. They not only treated broken jaws, mandibular dislocation, and various tumors, but also when serving as a military surgeon, improved the management of gunshot wounds and developed a technique for the localization and removal of bullets [10]. The first textbook on what can be considered oral surgery was written by the French surgeon Anselme Jourdain in 1778 [8]. In the United States in the 1800s there were a small group of physicians with dental training who practiced oral surgery as a branch of surgery. Among the outstanding members of this group was Simon P. Hullihen (1810-1857) (Fig. 4) of Wheeling, West Virginia [11]. During the last 10 years of his life, among other surgical procedures, he performed 100 cleft lip and 50 cleft palate operations, treated 100 cancers, did 200 procedures for maxillary sinus diseases, and performed 85 reconstructions of the lips, nose and mandible, a remarkable record at a time when local and general anesthesia did not exist. He also performed the first documented case of orthognathic surgery (for a detailed history of the development of orthognathic surgery see Ref. [12]). It was for the first time defined the true scope of oral surgery which later expanded and published under the title "A System of Oral Surgery". A review of the textbook in Dental Cosmos published in 1872 [13] stated: "Dr. Garretson's new work furnishes the missing link needed to unite dentistry with medicine and surgery, supplying a deficiency on either side and creating a new specialty - that of oral surgery." As the person who gave the discipline its name, Dr. Garretson is considered the founder of the specialty.From the 1800 s to the present time the scope of oral surgery gradually increased. Among the important factors contributing to this was the experience gained from the treatment of traumatic war injuries during these years. This was recognized in the 4th century by Hippocrates who stated: "War is the only proper school for a surgeon" [14]from last few years till today in the era of 2017 surgeons are planning for reconstruction or replacement of complete maxillofacial region.

\section{Conclusion}

Oral and maxillofacial surgery is a specialty that differs from any other specialty in medicine or dentistry. Originally arising from medicine, it eventually became a dentally based specialty, with both professions contributing to its ultimate scope. To this day it remains unique in that it is still the one specialty that continues to bridge medicine and dentistry in its education and training. Numerous changes in the trend have occurred in this field. The procedure which was limited to oral surgery like extractions, impactions and pre prosthetic surgeries have regained to oral and maxillofacial region including trauma, pathology, temporomandibular joint disorders and renovated the field to reconstructive surgeries of head and neck including dental implantology.The field is now termed as craniofacial surgery

[1]. Alumni Celebration June 17-18, 2011

\section{References}

[2]. "A History of OMS at Mass General" by Dr. Walter Guralnick.

[3]. "Keeping Ether in Vogue" by Drs. Guralnick and Kaban.

[4]. Rowe NL. The history of the treatment of maxillofacial trauma. Ann Roy Coll Surg Eng 1971;49:329-49.

[5]. Guerini V. A history of dentistry from the most ancient times until the end of the eighteenth century. Philadelphia: Lea \& Febiger; 1909.

[6]. Densham A. A review of the progress of dental science and literature from the earliest ages. Proc R Soc Med 1909;2:71-98.

[7]. Adams F. The Seven Books of Paulus Aegineta. London: Sydenham Society; 1846. 
[8]. Garant PR. The long climb from dental surgeons to doctors of dental surgery. Chicago: Quintessence Publishing Co.; 2013.

[9]. Hoffmann-Axhelm W. History of dentistry. Chicago: Quintessence Publishing Co.; 1981.

[10]. Packard FR. Life and times of Ambroise Pare. New York: Paul B. Hoeber; 1921.

[11]. Aziz SR, Simon P. Hullihen and the origin of orthognathic surgery. J Oral Maxillofac Surg 2004;62:1303-7.

[12]. Steinhauser EW. Historical development of orthognathic surgery. J Cranio Maxillofac Surg 1996;24:195-204.

[13]. The future of dentistry. Dent Cosmos 1872;14:608-11.

[14]. Daniel M. Laskin. Oral and maxillofacial surgery: The mystery behind the history $*$ Journal of Oral and Maxillofacial Surgery, Medicine, and Pathology 2015 (460)1-4. 